\title{
Intellectual property management: Building strategic appropriation advantage for emerging nano-economy
}

\author{
Majid Hussain Qadri ${ }^{*}$ and Uzma Qadri ${ }^{2}$ \\ ${ }^{1}$ The Business School, University of Kashmir, ${ }^{2}$ Department of Law, University of Kashmir \\ *Email: majidqadri@kashmiruniversity.ac.in
}

The emerging nano-technology driven economy is in incessant need for new Intellectual Property (IP) management practice-theory paradigm [1] that enables it to respond to new opportunities, challenges and alternative modes of intra-firm and inter-firm innovations to understand the hypercompetition consequences for firm's business that has stretched-out far beyond the legal aspects of an IP-related dispute. IP management traditionally focused on allowing freedom of operation in R\&D and mitigating the risk of imitation by competitors, firms increasingly apply it in combination with business strategy to fence or steer technological paths, to operate on secondary markets for technology, to respond to competitive moves, and to implement alternative business models. No doubt IP management has been investigated from a variety of theoretical and disciplinary perspectives, but managers, scholars, and educators are in search of practical case studies that illuminate candidly the relevance, generalization, successes, and failures of particular IP management practices, strategies, and business models.

Intellectual Property management emerges as a key component of what we call "appropriation advantage"[2]. We define appropriation advantage as an actors' ability to outperform competitors in terms of taking possession of and extracting value from knowledge and technology for productive activities. Consistent with David Teece's work [2, 3] and based on the case-study illustrated in the paper, we argue that IP cannot be seen as the logical consequence or the footnote of a go-to-market strategy. Instead, we emphasize that an original IPbased strategy can enable companies to differentiate themselves from competitors. As such, IP assets become a fundamental ingredient to achieve appropriation advantage. The paper shall develop a framework for the emerging nano-economy based on the grounded theory paradigm through identification of three main IP challenges [4] that need to be addressed to build such an appropriation advantage:

- managing tensions between technological integration and IP fragmentation,

- increasing return on IP investment, and

- organizing IP implementation.
The purpose of this conceptual research paper is to provide a taxonomy about how companies can process ideation-plan-execute continuum practices to manage IP assets, implement IP strategies, and carry out IP-based business models in a emerging nano-economy landscape. The research methodology appropriate for the such nanoscenarios study adopted shall be the case-study methodology in order to understand the research problematisation in its emerging contextual frameworks holistically. Providing an in-depth case study of IMEC, a Belgian research institute that orchestrates several innovation ecosystems around specific nano-electronics technologies, we postulate that smart combinations of different IP arrangements (i.e., generic versus exclusive) allow each ecosystem partner to build up a unique IP fingerprint that maximizes their ability to appropriate value from the joint innovation activities. At the same time, this IP taxonomy enables the orchestrator to generate the necessary freedom to continuously initiate new innovation ecosystems (as in the contemporary multi-invention contexts, private and public firms increasingly organize themselves into ecosystems to achieve joint innovative goals while sharing associated costs and risks). The present case-study shall print-out the importance of particular IP arrangements for the successful governance of such ecosystems. The paper propounds the need for an integrated view on IP of nano-economy and identifies the challenges and opportunities that emerge as industry; and for academia to consider this perspective to further their research and practice.

\section{References}

1. H. Chesbrough, Open Innovation: The New Imperative for Creating and Profiting from Technology (Boston, MA: Harvard Business School Press, 2006).

2. D. Teece, "Profiting from Technological Innovation: Implications for Integration, Collaboration, Licensing and Public Policy," Research Policy, 15/6 (December 1986): 285-305.

3. D. Somaya, D. Teece, and S. Wakeman, "Innovation in Multi-Invention Contexts: Mapping Solutions to Technological and Intellectual Property Complexity," California Management Review, 53/4 (Summer 2011): 47-79.

4. A.Minin, and D.Faems, "Appropriation Advantage:An Introduction to the Special Issue on Intellectual Property Management", California Management Review, Vol. 55, no. 4,(2013), 7-14. 